\title{
Minute Times Picogram per Milliliter per Meter Squared
}

National Cancer Institute

\section{Source}

National Cancer Institute. Minute Times Picogram per Milliliter per Meter Squared. NCI

Thesaurus. Code C111273.

Minutes times picograms per milliliter, divided by meters squared. 